\title{
MP
}

\section{Gender and ethnicity modify the association between the CYP1A2 rs762551 polymorphism and habitual coffee intake: evidence from a meta-analysis}

\author{
S. Denden ${ }^{1,2}$, B. Bouden ${ }^{1}$, A. Haj Khelil' ${ }^{1}$ J. Ben Chibani' ${ }^{1}$ and M.H. Hamdaoui ${ }^{3}$ \\ ${ }^{1}$ Research Unit on Biology and Molecular Anthropology Applied to Development \\ and Health, Faculty of Pharmacy, University of Monastir, Monastir, Tunisia \\ ${ }^{2}$ High School for Health Sciences and Technicals, \\ University of Tunis El-Manar, Tunis, Tunisia \\ ${ }^{3}$ Research Unit on the Antioxidant Compounds, Oxidative Stress, \\ Trace Elements and Metabolic Diseases, \\ High School for Health Sciences and Technicals, \\ University of Tunis El-Manar, Tunis, Tunisia \\ Corresponding author: S. Denden \\ E-mail: denden_sabri@yahoo.fr
}

Genet. Mol. Res. 15 (2): gmr.15027487

Received August 20, 2015

Accepted November 18, 2015

Published April 4, 2016

DOI http://dx.doi.org/10.4238/gmr.15027487

ABSTRACT. The association between the single nucleotide polymorphism rs762551 in the cytochrome P450 family 1, subfamily A2 gene (CYP1A2) and caffeine consumption remains controversial. We conducted a metaanalysis to clarify this potential association. Twelve studies were selected from articles retrieved from the and Google Scholar databases, and the data were analyzed to determine the odds ratio (OR) of genotypes $A A$ (conferring fast caffeine metabolism) vs AC + CC (conferring slow caffeine metabolism). Comparisons were made between 6161 high caffeine consumers and 3219 low caffeine consumers. The overall analysis showed a significant association between genotype AA and coffee intake 
[OR $=1.13,95 \%$ confidence interval $(C l)=1.03-1.24 ; Q=19.23, P=$ $0.06 ; l^{2}=43 \%$ ]. In subgroup analyses, the association was also found within male, younger, and Caucasian subjects $(\mathrm{OR}=1.21,95 \% \mathrm{Cl}=1.08$ $1.35 ; \mathrm{OR}=1.71,95 \% \mathrm{Cl}=1.18-2.48 ; \mathrm{OR}=1.29,95 \% \mathrm{Cl}=1.12-1.49$, respectively) but not in female, older, and Asian subjects (OR $=0.98$, $95 \% \mathrm{Cl}=0.83-1.15 ; \mathrm{OR}=0.83,95 \% \mathrm{Cl}=0.56-1.22 ; \mathrm{OR}=0.91,95 \% \mathrm{Cl}$ $=0.71-1.17$, respectively). Therefore, the rs762551 AA genotype may lead to higher coffee intake, especially in males, younger age groups, and individuals of Caucasian ethnicity. Our data highlight the need to test other CYP1A2 polymorphisms showing significance in genome-wide association studies to clarify the association with caffeine intake in the Asian population.

Key words: CYP1A2; rs762551 SNP; Coffee intake; Meta-analysis; Ethnicity

\section{INTRODUCTION}

Coffee consumption has become a growing concern for the general public since epidemiological studies have suggested an association between caffeine intake and several pathologies. In fact, long-term caffeine intake has been associated with an increased risk of myocardial infarction and recurrent pregnancy loss but with a decreased risk of type 2 diabetes and Parkinson's disease. Studies on the association between caffeine and cancer showed an increasing risk for ovarian, bladder, and lung cancers but a protective effect of high coffee consumption against breast, colon, prostate, and liver cancers. Environmental, demographic, and social factors may explain the observed inter-individual variability in caffeine intake. However, twin studies have provided evidence of heritability determinants of caffeine intake, suggesting that individual differences in caffeine consumption may be related to genetic factors (Vink et al., 2009). Genome-wide association studies (GWAS) of habitual coffee intake showed significant associations of different gene sequence variants with increased coffee intake, mainly cytochrome P450 family 1, subfamily A1-A2 (CYP1A1-CYP1A2), aryl hydrocarbon receptor (AHR; Cornelis et al., 2011), neuronal cell adhesion molecule (NRCAM; Amin et al., 2012) and taste receptor type 2, family member 43 (TAS2R43; Pirastu et al., 2014) loci. These genes have been implicated in caffeine metabolism, regulation of metabolism-related genes, vulnerability to addiction, and coffee taste preferences, respectively.

Caffeine is primarily metabolized by CYP1A2, and genetic variations altering the expression of the enzyme represent a major determinant of enzyme activity. A single nucleotide polymorphism (SNP) in the CYP1A2 gene $(-163 A \rightarrow C, r s 762551)$ was found to be correlated with altered enzyme activity, as $\mathrm{C}$ allele carriers showed decreased activity of the enzyme (Sachse et al., 1999). However, the relationship between the rs762551 SNP and coffee consumption remains controversial, owing to conflicting data obtained from GWAS and single-marker association studies. In order to provide further information about the association between the rs762551 SNP and coffee drinking, we conducted a meta-analysis using new data extracted from published studies evaluating the distribution of rs762551 genotypes among subjects stratified according to coffee intake. 


\section{MATERIAL AND METHODS}

\section{Study selection and inclusion criteria}

We searched the and Google Scholar databases for published papers by using combinations of the following terms: "cyp1A2", "cyp1A2 polymorphism", "caffeine", "coffee", "rs762551". The search was conducted up until June 4, 2015. GWAS on the association of the rs762551 SNP with caffeine intake were not included. In addition, we avoided using data from patients as they may show differences in terms of the distribution of the rs762551 genotypes and coffee consumption compared to healthy subjects. All studies that evaluated the interaction of the rs762551 SNP with coffee intake in disease susceptibility, or showing the distribution of rs762551 genotypes according to coffee intake strata in relation to a particular phenotype were screened. Data on ethnic origin, mean age, gender ratio, smoking status (never-smoking, current smoker), and rs762551 genotype counts among coffee consumption groups were extracted from the control group data sets. Several studies provided combined AC + CC genotype frequency counts in order to assess the associations between fast caffeine metabolizers (AA genotype) vs low caffeine metabolizers ( $A C+C C$ genotypes). We consequently used the dominant CYP1A2 C allele model for this meta-analysis. Hardy Weinberg equilibrium (HWE) conformation was assessed in studies reporting separate CA and CC genotype counts.

\section{Data analysis}

For each study, individuals were stratified according to coffee consumption based on the number of cups of coffee consumed per day, amount of caffeine intake per day, never vs ever coffee drinkers, null vs weekly vs daily coffee drinkers, no/low consumers vs moderate consumers vs high consumers, non-heavy coffee consumers vs heavy coffee consumers, or low vs high intake. We examined the association of the CYP1A2 rs762551 SNP with coffee intake by comparing the $A A$ and $A C+C C$ genotype distributions among the coffee consumption categories. In particular, the following groups were compared in the meta-analysis: the highest coffee consumption group ( $\geq 2$ coffee cups consumed per day, $\geq 200 \mathrm{mg} /$ day caffeine intake, ever drinkers, daily drinkers, high consumers, heavy coffee consumers, or high intake) vs the lowest coffee consumption group (reference group).

\section{Statistical analysis}

We checked the conformation of genotype frequencies to HWE using the HWE web tool (http://ihg.gsf.de/cgi-bin/hw/hwa1.pl). Meta-analysis statistics were derived using the Review Manager Program version 5.3 (Cochrane Collaboration, Oxford, UK). Odds ratios (ORs) and 95\% confidence intervals $\left(95 \% \mathrm{Cls}\right.$ ) were estimated for each study. Cochran's $Q$ (or $\left.\chi^{2}\right)$ and $l^{2}$ values were used to assess heterogeneity among studies. Either fixed- or random-effect models were chosen according to heterogeneity between studies. The random-effect model was used when a significant $Q$ value $(P<0.05)$ was calculated. There was no need to examine the influence of publication bias since data for genotype distributions and coffee intake were derived from separate, independent studies and none directly examined the association between the rs762551 AA genotype and coffee intake. To investigate evidence for any confounding variable that may modify the effect of the 
rs762551 AA genotype, we further conducted sub-analyses by stratifying the data according to gender, age, smoking status, and ethnicity. For example, if smoking modifies the genetic effect on caffeine intake, the OR of the AA genotype in the comparison of high vs low caffeine consumers would differ between never-smokers and current smokers. The Cochran test given a statistically significant result $(P<0.05)$ indicates the OR difference across the stratified data and indicates the existence of an effect modification.

\section{RESULTS}

\section{Studies included in the meta-analysis}

Thirty-three studies were assessed for eligibility. The following papers were excluded: four GWAS (Cornelis et al., 2011; Sulem et al., 2011; Amin et al., 2012; Rodenburg et al., 2012); four studies lacking coffee intake analysis (Sachse et al., 1999; Basvi et al., 2007; Ghotbi et al., 2007; Gunes et al., 2009); eight studies not providing coffee intake data according to rs762551 genotypes (Goodman et al., 2003; Kotsopoulos et al., 2009; Hallström et al., 2010; Schmidt et al., 2010; Guessous et al., 2012; Josse et al., 2012; Palatini et al., 2015; Yamamoto et al., 2015); two studies providing $C C$ and combined $A C+A A$ genotypes counts instead of $A A$ and $A C+C C$ genotype counts (Palatini et al., 2009; Pavanello et al., 2010); two studies using patient samples (Cornelis et al., 2007; Bågeman et al., 2008); and one study with a small sample size (Santos et al., 2015). Finally, 12 studies were included in the meta-analysis (Nordmark et al., 2002; Sata et al., 2005; Cornelis et al., 2006; Kotsopoulos et al., 2007; Tan et al., 2007; Jernström et al., 2008; Djordjevic et al., 2010; Popat et al., 2011; Kohno et al., 2013; Lowcock et al., 2013; Tian et al., 2013; Dik et al., 2014) (Figure 1). The study characteristics are shown in Table 1. Samples showing deviations from HWE ( $\mathrm{P}$ < 0.05) were not included. In total, comparisons were made between 6161 high caffeine consumers and 3219 low caffeine consumers.

Table 1. Characteristics of studies included in the meta-analysis.

\begin{tabular}{|c|c|c|c|c|c|c|c|c|c|c|c|c|}
\hline \multirow[t]{2}{*}{ References } & \multirow[t]{2}{*}{ Location } & \multirow[t]{2}{*}{ Ethnicity } & \multirow[t]{2}{*}{$\begin{array}{l}\text { Mean age } \\
\text { (years) }\end{array}$} & \multirow[t]{2}{*}{$\begin{array}{l}\text { Gender ratio } \\
\text { Male/Female }\end{array}$} & \multicolumn{2}{|c|}{ Coffee intake ascertainment } & \multicolumn{2}{|c|}{$\begin{array}{l}\text { rs762551 (AA) } \\
\text { genotype (N) }\end{array}$} & \multicolumn{2}{|c|}{$\begin{array}{l}\text { rs762551 }(\mathrm{AC}+\mathrm{CC}) \\
\text { genotypes }(\mathrm{N})\end{array}$} & \multirow{2}{*}{$\begin{array}{l}\text { rs762551 } \\
\text { A allele } \\
\text { frequency }\end{array}$} & \multirow[t]{2}{*}{ HW } \\
\hline & & & & & High intake & Low intake $^{\mathrm{b}}$ & $\begin{array}{c}\begin{array}{c}\text { High } \\
\text { intake }\end{array} \\
\end{array}$ & $\begin{array}{l}\begin{array}{c}\text { Low } \\
\text { intake }\end{array} \\
\text { int }\end{array}$ & $\begin{array}{c}\begin{array}{c}\text { High } \\
\text { intake }\end{array} \\
\text { in }\end{array}$ & $\begin{array}{l}\text { Low } \\
\text { intake }\end{array}$ & & \\
\hline Cornelis et al. (2006) & Canada & Hispanic American $^{\mathrm{a}}$ & 58.1 & $73.8 / 26.2$ & \begin{tabular}{|l}
$\geq 2$ cups/day \\
\end{tabular} & $<1$ cup/day & 661 & 113 & 746 & 156 & 0.73 & $\mathrm{NA}$ \\
\hline Dik et al. (2014) & Netherland & Caucasian & 51.2 & $29.8 / 70.2$ & High consumers & $\begin{array}{l}\text { Non/low } \\
\text { consumers }\end{array}$ & 387 & 293 & 329 & 307 & 0.75 & NA \\
\hline \multirow[t]{2}{*}{ Djorjevic et al. (2010) } & Sweden & Caucasian & 26 & $41.2 / 58.8$ & Heavy consumers & $\begin{array}{l}\text { Non-heavy } \\
\text { consumers }\end{array}$ & 21 & 25 & 21 & 47 & 0.70 & $0.002^{\star}$ \\
\hline & Serbia & Caucasian & 27 & $47.6 / 53.4$ & Heavy consumers & $\begin{array}{l}\text { Non-heavy } \\
\text { consumers }\end{array}$ & 10 & 12 & 7 & 35 & 0.67 & 0.75 \\
\hline Sata et al. $(200$ & Japan & Asian & $19-44$ & $0 /$ & $>300 \mathrm{mg} / \mathrm{day}$ & $<100 \mathrm{mg} /$ day & 6 & 34 & 11 & 31 & 0.74 & 0.45 \\
\hline Jernstrom et al. & Sv & (cas & - & & $\geq 2$ cups/day & $<1 \mathrm{cu}$ & 79 & 43 & 78 & 43 & 0.75 & NA \\
\hline Kohno et al. (2) & & $n^{2}$ & 52 & & Daliy use & Null use & 450 & 86 & 579 & 98 & 0.72 & NA \\
\hline Kotsopoulos $\mathrm{e}$ & & ucasian & & & ver & Never use & 81 & $\frac{41}{146}$ & $\begin{array}{l}89 \\
365\end{array}$ & 30 & 0.75 & $\begin{array}{l}\mathrm{NA} \\
037\end{array}$ \\
\hline Lowc & \begin{tabular}{|l|l|} 
Canada \\
\end{tabular} & cata & 25 & & 22 cups/d & Neve & 376 & 14 & 365 & 16 & 0.75 & 0.37 \\
\hline 2002) & \begin{tabular}{|l|} 
Sweden \\
\end{tabular} & Caucas & 28 & & \begin{tabular}{|l} 
High intake \\
Fyer we
\end{tabular} & $\begin{array}{l}\text { Low intake } \\
\end{array}$ & $\frac{195}{523}$ & $\frac{259}{128}$ & $\frac{199}{475}$ & $\frac{251}{160}$ & 0.75 & 0.93 \\
\hline Pop & \begin{tabular}{|l} 
USA \\
Singa
\end{tabular} & $\frac{\mathrm{C}}{\mathrm{C}} \mathrm{s}$ & $\frac{6}{6}$ & $\frac{65}{51}$ & \begin{tabular}{|l|l|} 
Ever \\
$>200$
\end{tabular} & 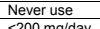 & 523 & $\frac{128}{67}$ & $\frac{475}{162}$ & 160 & 0.75 & 0.65 \\
\hline Tan et al. (2007) & \begin{tabular}{|l} 
Singapore \\
\end{tabular} & Asian & 63.6 & $51.5 / 48.5$ & $>200 \mathrm{mg} / \mathrm{day}$ & $<200 \mathrm{mg} / \mathrm{day}$ & 161 & 67 & 162 & 65 & 0.75 & 0.14 \\
\hline Tian et al. (2013) & \begin{tabular}{|l|l|} 
Canada \\
\end{tabular} & Caucasian/Asian & 22.7 & $29 / 71$ & $>200 \mathrm{mg} / \mathrm{day}$ & $<100 \mathrm{mg} /$ day & 102 & 303 & 90 & 359 & 0.73 & NA \\
\hline
\end{tabular}

aHispanic Americans were treated as Caucasians. ${ }^{b}$ Reference group; HWE = Hardy-Weinberg equilibrium; NA = not applicable; *HWE P $<0.05$ (the sample was excluded).

\section{Overall analysis}

Data from the 12 included studies were analyzed to obtain the OR of the AA genotype (fast caffeine metabolizer) vs AC + CC genotypes (slow caffeine metabolizer) in relation to coffee intake. Figure 2 shows the individual ORs for each study, as well as the total OR. The fixed-effect model 
was used given the overall low level of heterogeneity $\left(Q=19.23, P=0.06 ; l^{2}=43 \%\right)$. Overall, there was a significant association between $A A$ genotype and coffee intake $(O R=1.13,95 \% \mathrm{Cl}=$ 1.03-1.24).

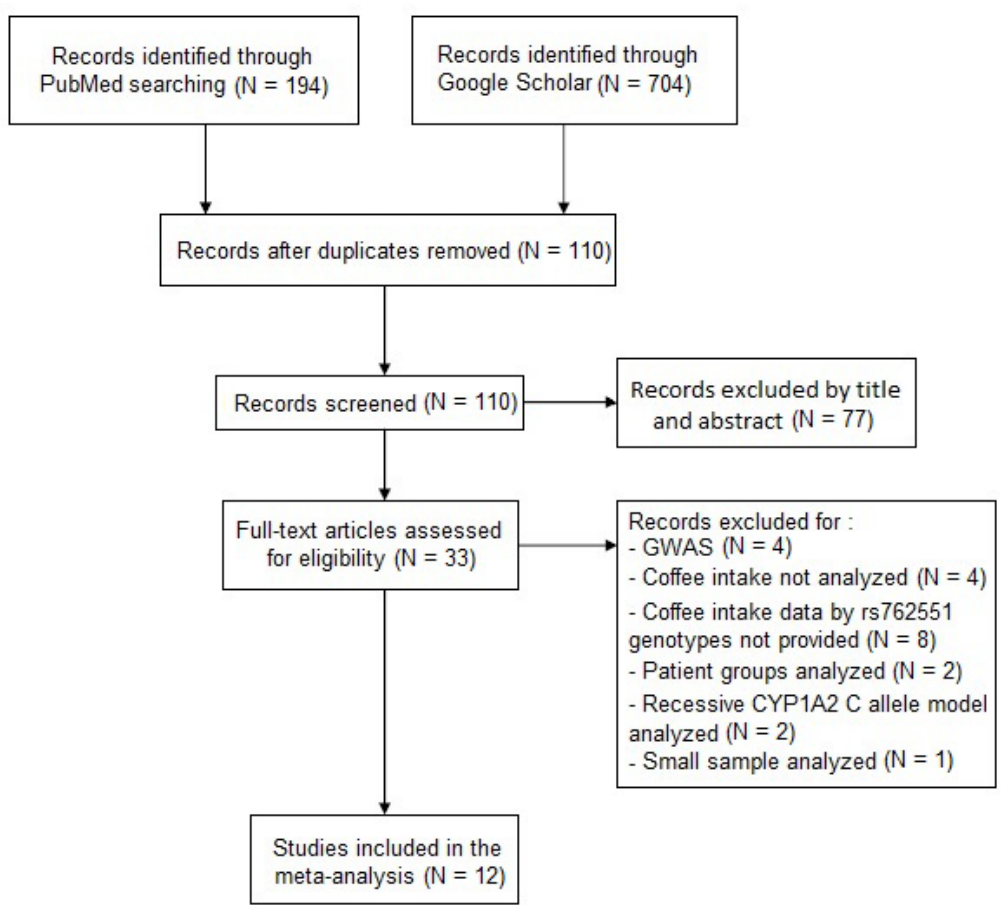

Figure 1. Flow chart for study selection. For Google Scholar records, only the first 200 articles of each search were assessed for eligibility.

\begin{tabular}{|c|c|c|c|c|c|}
\hline Study & $\begin{array}{l}\text { Odds Ratio } \\
\text { M-H, Fixed, } 95 \% \mathrm{Cl}\end{array}$ & & $\begin{array}{r}\text { Od } \\
M-H, F\end{array}$ & $\begin{array}{l}\text { ds Ratio } \\
\text { xed, } 95 \% \mathrm{Cl}\end{array}$ & \\
\hline Cornelis, 2006 & $1.22[0.94,1.59]$ & & & -- & \\
\hline Dik, 2014 & $1.23[0.99,1.53]$ & & & $=$ & \\
\hline Djordjevic, 2010 & $4.17[1.30,13.39]$ & & & & \\
\hline Jernstrom, 2008 & $1.01[0.60,1.71]$ & & & & \\
\hline Kohno, 2013 & $0.89[0.65,1.21]$ & & & & \\
\hline Kotsopoulos, 2007 & $0.67[0.38,1.16]$ & & & & \\
\hline Lowcock, 2013 & $1.14[0.87,1.48]$ & & & $=$ & \\
\hline Nordmark, 2001 & $0.95[0.73,1.24]$ & & & & \\
\hline Popat, 2011 & $1.38[1.06,1.79]$ & & & $=$ & \\
\hline Sata, 2005 & $0.50[0.16,1.51]$ & & & - & \\
\hline $\tan , 2007$ & $0.96[0.64,1.45]$ & & & & \\
\hline Tian, 2013 & $1.34[0.97,1.84]$ & & & & \\
\hline Total $(95 \% \mathrm{Cl})$ & $1.13[1.03,1.24]$ & & & $\bullet$ & \\
\hline \multirow{2}{*}{\multicolumn{2}{|c|}{$\begin{array}{l}\text { Total events } \\
\text { Heterogeneity: } \mathrm{Chi}^{2}=19.23, \mathrm{df}=11(\mathrm{P}=0.06) ; \mathrm{I}^{2}=43 \%\end{array}$}} & & & & \\
\hline & & $\begin{array}{cc}1 & 1 \\
0.1 & 0.2\end{array}$ & 0.5 & 2 & 5 \\
\hline
\end{tabular}

Figure 2. Forest plot of the odds ratios of individual studies and overall odds ratio for the association of coffee intake with the rs762551 AA genotype with $(A C+C C)$ genotypes. 


\section{Subgroup analyses}

Stratification of the data by gender was not possible within studies. However, inter-study differences between the genders evaluated and gender ratios were evident. Indeed, there were studies including only one gender in the control group, in order to match cases for gender (e.g., association studies on breast cancer risk used fertile women as a control group). Therefore, a subgroup analysis was performed within the 5 studies $(\mathrm{N}=2518)$ comprising only female subjects ( $\mathrm{F}$ subgroup) and within the 7 remaining studies ( $N=6862)$ with an overall male/female gender ratio of 57.8/42.2 (MF subgroup). This meta-analysis showed that the rs762551 AA genotype was associated with coffee intake in the MF subgroup (fixed-effects model OR $=1.21,95 \% \mathrm{Cl}=1.08-1.35 ; \mathrm{Q}=10.94, \mathrm{P}=0.09 ; I^{2}=$ $45 \%$ ) but not in the $\mathrm{F}$ subgroup (fixed-effect model $\mathrm{OR}=0.98,95 \% \mathrm{Cl}=0.83-1.15 ; \mathrm{Q}=4.53, \mathrm{P}=0.34$; $R^{2}=12 \%$ ), with evidence for an effect modification ( $P$ value for heterogeneity $=0.04$ ) (Figure 3 ).

A subgroup analysis according to smoking was also performed using data extracted from studies that analyzed the rs762551 genotype distribution according to both coffee consumption and smoking status. A total of 2633 never-smoker subjects were compared to 1155 current smokers. We found that the rs762551 AA genotype was not associated with coffee intake in either the never smokers (fixed-effect model $\mathrm{OR}=1.04,95 \% \mathrm{Cl}=0.87-1.25 ; \mathrm{Q}=2.94, \mathrm{P}=0.23 ; \mathrm{I}^{2}=32 \%$ ) or current smokers (fixed-effect model $\mathrm{OR}=1.09,95 \% \mathrm{Cl}=0.75-1.58 ; \mathrm{Q}=0.28, \mathrm{P}=0.87 ; I^{2}=0 \%$ ), with no evidence of any effect modification by smoking ( $P$ value for heterogeneity $=0.83$ ) (Figure 3 ).

Furthermore, data on rs762551 genotypes stratified by both coffee consumption and age were available in only one study; 831 subjects younger than 59 years and 845 subjects 59 years of age or older were assessed. We found that the rs762551 AA genotype was associated with coffee intake in subjects younger than 59 years $(\mathrm{OR}=1.71,95 \% \mathrm{Cl}=1.18-2.48)$, whereas no association was detected in those aged 59 years or older $(\mathrm{OR}=0.83,95 \% \mathrm{Cl}=0.56-1.22)$. In this case, the effect modification by age was significant $(P=0.008)$ (Figure 3 ).

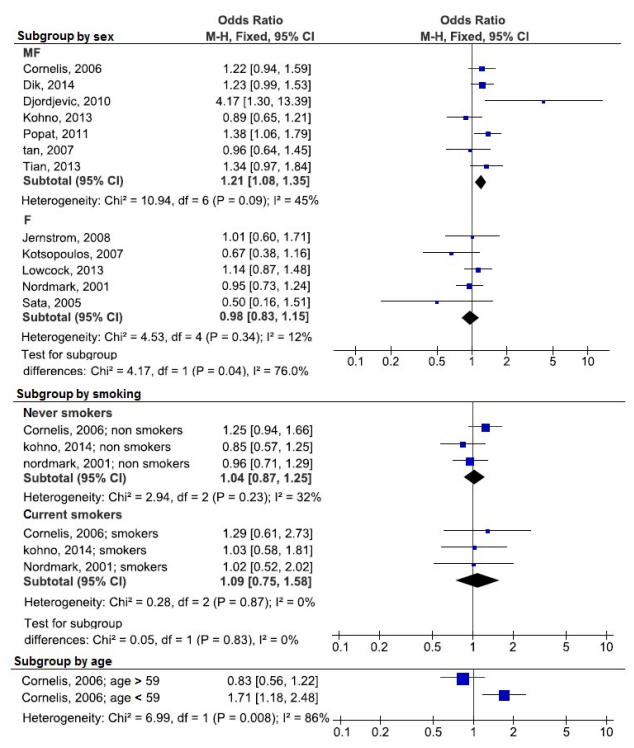

Figure 3. Forest plot of the odds ratios of individual studies and total odds ratio for the association of coffee intake with the rs762551 SNP, pooled by sex, smoking, and age. F: female only; MF: male/female ratio of 57.8/42.2. 
Finally, an ethnicity-specific meta-analysis was conducted. Seven studies $(\mathrm{N}=6778)$ included subjects of Caucasian ethnicity and 3 studies $(N=1750)$ used individuals of Asian ethnicity. One study was excluded since the analyzed sample was ethnically heterogeneous (Caucasians, 47\%; Asians, 46\%; others, 8\%). As a result, the Caucasians subgroup showed a significant relationship between AA genotype and coffee intake (fixed-effect model OR $=1.16$, $95 \% \mathrm{Cl}=1.04-1.29 ; \mathrm{Q}=12.97, \mathrm{P}=0.07 ; I^{2}=46 \%$ ), whereas Asians did not show any association (fixed-effect model $\mathrm{OR}=0.89,95 \% \mathrm{Cl}=0.70-1.13 ; \mathrm{Q}=1.21, \mathrm{P}=0.55 ; l^{2}=0 \%$ ). However, the test for subgroup differences did not reach significance $(P=0.05)$, although when we tested the relationship within the MF subgroup, the effect modification was significant $(P=0.02)$. The OR of the association between AA genotype and coffee intake in Caucasian subjects from the MF subgroup $(\mathrm{N}=4342)$ was $1.29\left(95 \% \mathrm{Cl}=1.12-1.49 ; \mathrm{Q}=4.43, \mathrm{P}=0.22 ; I^{2}=32 \%\right)$, whereas Asians from the MF subgroup $(N=1668)$ did not show any significance $(\mathrm{OR}=0.91,95 \% \mathrm{Cl}=0.71-1.17 ; \mathrm{Q}$ $=0.11, \mathrm{P}=0.75 ; l^{2}=0 \%$ ) (Figure 4 ).

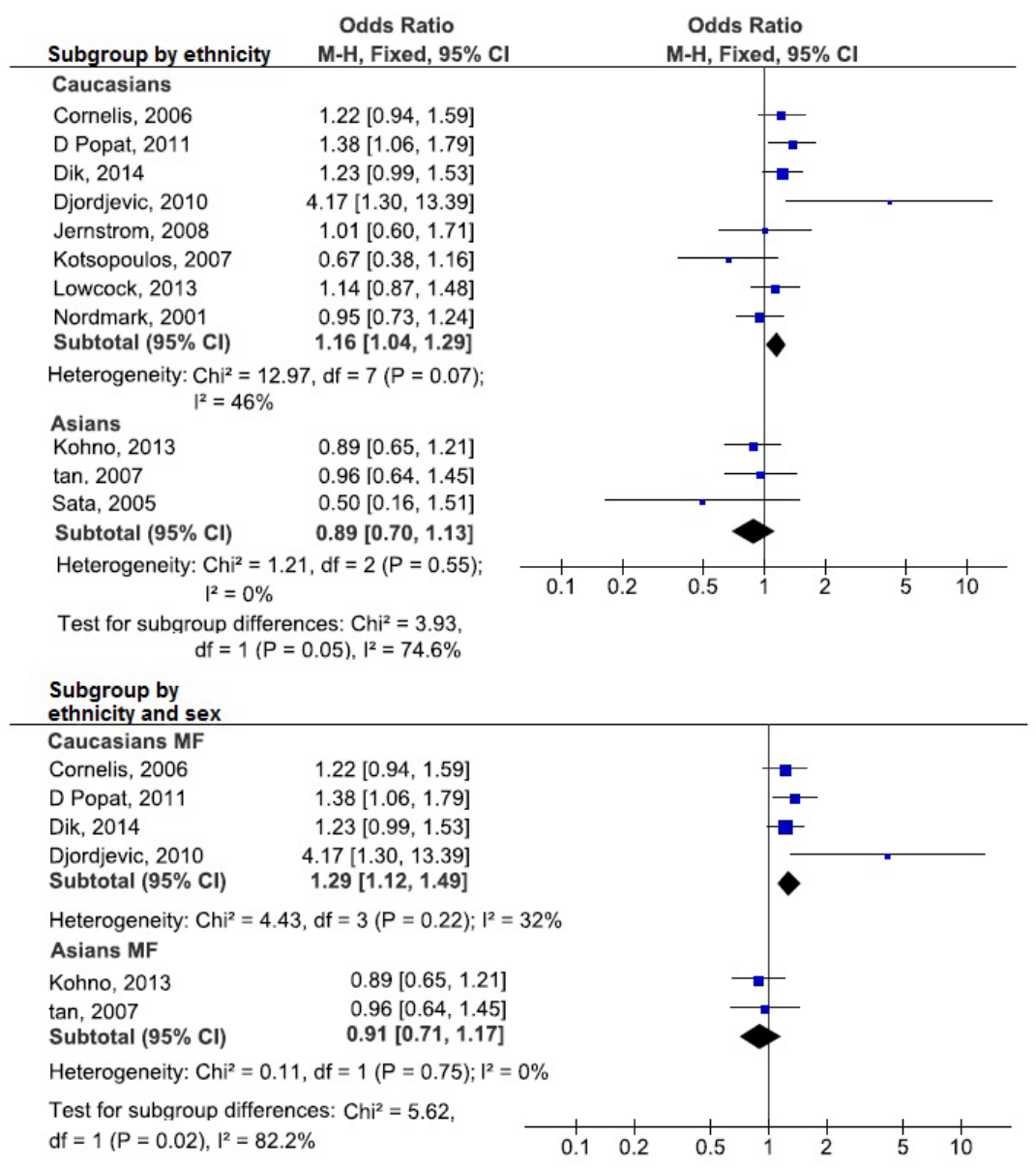

Figure 4. Forest plot of the odds ratios of individual studies and total odds ratio for the association of coffee intake with the rs762551 SNP, pooled by ethnicity and ethnicity + sex. MF: male/female ratio of 57.8/42.2. 


\section{Interaction of coffee intake with smoking, gender, age, and ethnicity}

The genotype distribution in relation to coffee consumption status (high coffee intake vs low intake) among subgroups was assessed by using the Pearson $\chi^{2}$ test. Coffee intake was significantly increased by smoking $(\mathrm{OR}=3.53,95 \% \mathrm{Cl}=2.90-4.31, \mathrm{P}<0.00001)$ and male gender $(\mathrm{OR}=1.5,95 \% \mathrm{Cl}=1.36-1.64, \mathrm{P}<0.00001)$. Individuals below 59 years of age showed a nonsignificant increase in coffee consumption $(\mathrm{OR}=1.30,95 \% \mathrm{Cl}=1.00-1.68, \mathrm{P}=0.051)$. With regards to ethnicity, Asians showed a significantly increased coffee intake compared to Caucasians $(\mathrm{OR}=$ $1.70,95 \% \mathrm{Cl}=1.50-1.93, \mathrm{P}<0.00001)$.

\section{DISCUSSION}

Our results of significant associations of male gender and smoking with higher coffee intake are in line with previous studies, suggesting lower CYP1A2 activity in women (Gunes and Dahl, 2008) and that smoking increases CYP1A2 enzyme activity (Backman et al., 2008). There was no significant association observed for age, which is also consistent with previous finding that smoking and gender are the main modifiers of CYP1A2 enzyme activity (24 and $10 \%$, respectively), whereas age explained only $1 \%$ of the variation in enzyme activity (Gunes et al., 2009). The first report on the CYP1A2 rs762551 SNP showed a significant correlation with high enzyme inducibility among smokers, while no correlation was observed for non-smokers (Sachse et al., 1999). Consequently, carriers of the C variant allele were considered to be slow caffeine metabolizers, whereas AA homozygous individuals were considered to be fast caffeine metabolizers. The association between the rs762551 SNP and coffee consumption was first assessed in a study conducted with Costa Rican subjects, and no significant association was found (Cornelis et al., 2007). Population-based GWAS for habitual coffee drinking also tested the association with the rs762551 SNP. Amin et al. (2012) conducted a GWAS and found nominal significance for the rs762551 SNP ( $P=0.003)$. Sulem et al. (2011) conducted a GWAS, and found that the rs762551 AA genotype was also nominally associated with increased coffee consumption $(P=0.008)$, but the significance disappeared after adjusting for another CYP1A1-CYP1A2 SNP (rs2472297), achieving genome-wide significance $\left(P=5.4 \times 10^{-14}\right)$. However, Rodenburg et al. (2012) showed that the A allele of the rs762551 SNP was linked to the G allele of the rs2472299 SNP (complete linkage disequilibrium), and the rs2472299 GG genotype significantly contributed to coffee intake ( $P<0.0002)$, even after adjusting for the rs2472297 SNP. Based on these 12 studies, we conducted a meta-analysis including 6161 high consumers and 3219 low consumers. We found that the rs762551 AA genotype was associated with higher coffee intake. These data were then subjected to stratification by gender, age, smoking status, and ethnicity. The rs762551 AA genotype was associated with coffee intake in the subgroup containing both sexes (MF) but no significant association was observed in the female-only $(F)$ subgroup, with evidence for effect modification ( $P$ $=0.04)$. With regards to smoking, no association was found in either the never smokers or current smokers subgroups, with no evidence of effect modification $(P=0.83)$. For the interaction with age, we found that the rs762551 AA genotype increased coffee intake in subjects younger than 59 years old but not in those 59 years of age or older, and a significant genotype effect modification was observed $(P=0.008)$. These data are in line with those of Rodenburg et al. (2012), who investigated the modifying effect of gender, age, and smoking on the relationship of the rs762551 SNP with coffee intake in 6288 participants from the Rotterdam cohort. The authors reported a significant 
interaction with gender $(P=0.049)$ but not with smoking $(P=0.79)$. However, they did not find any interaction with age $(P=0.16)$. However, our finding of a significant effect modification from age is limited by the small size of the sample analyzed for age interaction $(\mathrm{N}=1676)$. The modifying effect of smoking was also evaluated by Guessous et al. (2012), but inconsistent results were obtained. Furthermore, a significant association of the CYP1A2 rs762551 AA genotype with high caffeine intake, assessed in 5452 subjects from the CoLaus study, was found among non-smokers ( $\mathrm{N}=$ 4017; $\mathrm{OR}=1.83,95 \% \mathrm{Cl}=1.38-2.45, \mathrm{P}<0.0001)$ but not in smokers $(\mathrm{N}=1435 ; \mathrm{OR}=1.15,95 \% \mathrm{Cl}$ $=0.79-1.67, \mathrm{P}=0.77$ ) with evidence for a significant effect modification. Another CYP1A1-CYP1A2 SNP (rs2472297), which showed GWAS significance in relation to coffee intake, was also tested for interactions with putative modifiers (Sulem et al., 2011). Stratification by smoking showed an association with coffee intake in both smokers $\left(P=1.9 \times 10^{-6}\right)$ and non-smokers $(P=0.00089)$, with no evidence for an effect modification $(P=0.83)$. However, no interaction effect was observed with gender $(P=0.47)$.

In the present meta-analysis, we further compared the data obtained from 7 studies including subjects of Caucasian origin and in 3 studies performed with subjects of Asian origin. Although Asians showed an overall increased coffee intake compared to Caucasians, a significant association between the AA genotype and coffee intake was only found in the Caucasians subgroup and not in Asians. A significant effect modification was also detected when comparing the association within the MF subgroup $(P=0.02)$. A similar finding, of a modification effect of ethnicity on the risk of rs762551 for cancer was previously reported (Wang et al., 2012). However, this is the first study to assess the relationship of rs762551 with coffee intake in the Asian population, since previous studies have only examined this association in European subjects. Ethnicity was suggested as a putative modifier factor for CYP1A2 enzymatic activity. Indeed, Ghotbi et al. (2007) reported that CYP1A2 activity was 1.54-fold higher in Swedes than in Koreans, independent of CYP1A2 rs762551 genotype. Perera et al. (2012) also showed significantly lower CYP1A2 activity in South Asian participants as compared to European participants. This reduced CYP1A2 activity in Asians carrying the rs762551 AA genotype could explain the lack of association with higher coffee intake in this population, suggesting that other genetic factors may be involved in the higher caffeine consumption observed in Asians. Our data highlight the need to test other CYP1A2 SNPs showing GWAS significance to determine the cause of the overall higher coffee intake in the Asian population.

There are some potential limitations to the current study. The coffee intake strata were assessed across studies. Furthermore, in the subgroup analysis by gender the comparison was made between male + female vs female instead of simply male vs female. Finally, only one study included in the meta-analysis analyzed the genotype interaction with age. Dealing with these concerns may provide a more accurate estimation of the association.

In conclusion, this meta-analysis showed that the CYP1A2 rs762551 AA genotype may lead to a higher coffee intake, particularly with male sex, younger age, and Caucasian ethnicity, but independent of smoking status. No association was found in people of Asian ethnicity. These data suggest that the genetic background leading to a higher coffee consumption may differ between ethnicities.

\section{ACKNOWLEDGMENTS}

The authors would like to thank the Ministry of Higher Education and Scientific Research in Tunisia for financial support of this study. 


\section{REFERENCES}

Amin N, Byrne E, Johnson J, Chenevix-Trench G, et al.; kConFab Investigators (2012). Genome-wide association analysis of coffee drinking suggests association with CYP1A1/CYP1A2 and NRCAM. Mol. Psychiatry 17: 1116-1129. http://dx.doi. org/10.1038/mp.2011.101

Backman JT, Schröder MT and Neuvonen PJ (2008). Effects of gender and moderate smoking on the pharmacokinetics and effects of the CYP1A2 substrate tizanidine. Eur. J. Clin. Pharmacol. 64: 17-24. http://dx.doi.org/10.1007/s00228-007$\underline{0389-y}$

Bågeman E, Ingvar C, Rose C and Jernström H (2008). Coffee consumption and CYP1A2*1F genotype modify age at breast cancer diagnosis and estrogen receptor status. Cancer Epidemiol. Biomarkers Prev. 17: 895-901. http://dx.doi. org/10.1158/1055-9965.EPI-07-0555

Basvi PT, Dandara C, Bapiro TE and Hasler J (2007). Role of CYP1A2*1F on CYP1A2 activity in a black African population as determined by caffeine phenotyping. J. Chinese Clin. Med 2: 211-214.

Cornelis MC, El-Sohemy A, Kabagambe EK and Campos H (2006). Coffee, CYP1A2 genotype, and risk of myocardial infarction. JAMA 295: 1135-1141. http://dx.doi.org/10.1001/jama.295.10.1135

Cornelis MC, El-Sohemy A and Campos H (2007). Genetic polymorphism of the adenosine A2A receptor is associated with habitual caffeine consumption. Am. J. Clin. Nutr. 86: 240-244.

Cornelis MC, Monda KL, Yu K, Paynter N, et al. (2011). Genome-wide meta-analysis identifies regions on 7p21 (AHR) and 15q24 (CYP1A2) as determinants of habitual caffeine consumption. PLoS Genet. 7: e1002033.

Dik VK, Bueno-de-Mesquita HB, Van Oijen MG, Siersema PD, et al. (2014). Coffee and tea consumption, genotype-based CYP1A2 and NAT2 activity and colorectal cancer risk-results from the EPIC cohort study. Int. J. Cancer 135: 401-412. http://dx.doi.org/10.1002/ijc.28655

Djordjevic N, Ghotbi R, Jankovic S and Aklillu E (2010). Induction of CYP1A2 by heavy coffee consumption is associated with the CYP1A2 -163C>A polymorphism. Eur. J. Clin. Pharmacol. 66: 697-703. http://dx.doi.org/10.1007/s00228-010-0823-4

Ghotbi R, Christensen M, Roh HK, Ingelman-Sundberg M, et al. (2007). Comparisons of CYP1A2 genetic polymorphisms, enzyme activity and the genotype-phenotype relationship in Swedes and Koreans. Eur. J. Clin. Pharmacol. 63: 537-546. http://dx.doi.org/10.1007/s00228-007-0288-2

Goodman MT, Tung KH, McDuffie K, Wilkens LR, et al. (2003). Association of caffeine intake and CYP1A2 genotype with ovarian cancer. Nutr. Cancer 46: 23-29. http://dx.doi.org/10.1207/S15327914NC4601 03

Guessous I, Dobrinas M, Kutalik Z, Pruijm M, et al. (2012). Caffeine intake and CYP1A2 variants associated with high caffeine intake protect non-smokers from hypertension. Hum. Mol. Genet. 21: 3283-3292. http://dx.doi.org/10.1093/hmg/dds137

Gunes A and Dahl ML (2008). Variation in CYP1A2 activity and its clinical implications: influence of environmental factors and genetic polymorphisms. Pharmacogenomics 9: 625-637. http://dx.doi.org/10.2217/14622416.9.5.625

Gunes A, Ozbey G, Vural EH, Uluoglu C, et al. (2009). Influence of genetic polymorphisms, smoking, gender and age on CYP1A2 activity in a Turkish population. Pharmacogenomics 10: 769-778. http://dx.doi.org/10.2217/pgs.09.22

Hallström H, Melhus H, Glynn A, Lind L, et al. (2010). Coffee consumption and CYP1A2 genotype in relation to bone mineral density of the proximal femur in elderly men and women: a cohort study. Nutr. Metab. (Lond) 7: 12. http://dx.doi. org/10.1186/1743-7075-7-12

Jernström H, Henningson M, Johansson $\mathrm{U}$ and Olsson $\mathrm{H}$ (2008). Coffee intake and CYP1A2*1F genotype predict breast volume in young women: implications for breast cancer. Br. J. Cancer 99: 1534-1538. http://dx.doi.org/10.1038/sj.bjc.6604687

Josse AR, Da Costa LA, Campos H and El-Sohemy A (2012). Associations between polymorphisms in the AHR and CYP1A1CYP1A2 gene regions and habitual caffeine consumption. Am. J. Clin. Nutr. 96: 665-671. http://dx.doi.org/10.3945/ ajcn.112.038794

Kohno M, Tajima O, Uezono K, Tabata S, et al. (2013). Cytochrome P450 1 A2 polymorphisms, coffee consumption and impaired glucose metabolism in Japanese men. Endocrinol. Metab. Syndr. 2: 119.

Kotsopoulos J, Ghadirian P, El-Sohemy A, Lynch HT, et al. (2007). The CYP1A2 genotype modifies the association between coffee consumption and breast cancer risk among BRCA1 mutation carriers. Cancer Epidemiol. Biomarkers Prev. 16: 912-916. http://dx.doi.org/10.1158/1055-9965.EPI-06-1074

Kotsopoulos J, Vitonis AF, Terry KL, De Vivo I, et al. (2009). Coffee intake, variants in genes involved in caffeine metabolism, and the risk of epithelial ovarian cancer. Cancer Causes Control 20: 335-344. http://dx.doi.org/10.1007/s10552-008-9247-1

Lowcock EC, Cotterchio M, Anderson LN, Boucher BA, et al. (2013). High coffee intake, but not caffeine, is associated with reduced estrogen receptor negative and postmenopausal breast cancer risk with no effect modification by CYP1A2 genotype. Nutr. Cancer 65: 398-409. http://dx.doi.org/10.1080/01635581.2013.768348

Nordmark A, Lundgren S, Ask B, Granath F, et al. (2002). The effect of the CYP1A2 *1F mutation on CYP1A2 inducibility in pregnant women. Br. J. Clin. Pharmacol. 54: 504-510. http://dx.doi.org/10.1046/j.1365-2125.2002.01673.x

Genetics and Molecular Research 15 (2): gmr.15027487

(CFUNPEC-RP www.funpecrp.com.br 
Palatini P, Ceolotto G, Ragazzo F, Dorigatti F, et al. (2009). CYP1A2 genotype modifies the association between coffee intake and the risk of hypertension. J. Hypertens. 27: 1594-1601. http://dx.doi.org/10.1097/HJH.0b013e32832ba850

Palatini P, Benetti E, Mos L, Garavelli G, et al. (2015). Association of coffee consumption and CYP1A2 polymorphism with risk of impaired fasting glucose in hypertensive patients. Eur. J. Epidemiol. 30: 209-217. http://dx.doi.org/10.1007/s10654$\underline{015-9990-z}$

Pavanello S, Mastrangelo G, Placidi D, Campagna M, et al. (2010). CYP1A2 polymorphisms, occupational and environmental exposures and risk of bladder cancer. Eur. J. Epidemiol. 25: 491-500. http://dx.doi.org/10.1007/s10654-010-9479-8

Perera V, Gross AS and McLachlan AJ (2012). Influence of environmental and genetic factors on CYP1A2 activity in individuals of South Asian and European ancestry. Clin. Pharmacol. Ther. 92: 511-519.

Pirastu N, Kooyman M, Traglia M, Robino A, et al. (2014). Association analysis of bitter receptor genes in five isolated populations identifies a significant correlation between TAS2R43 variants and coffee liking. PLoS One 9: e92065. http:// dx.doi.org/10.1371/journal.pone.0092065

Popat RA, Van Den Eeden SK, Tanner CM, Kamel F, et al. (2011). Coffee, ADORA2A, and CYP1A2: the caffeine connection in Parkinson's disease. Eur. J. Neurol. 18: 756-765. http://dx.doi.org/10.1111/j.1468-1331.2011.03353.x

Rodenburg EM, Eijgelsheim M, Geleijnse JM, Amin N, et al. (2012). CYP1A2 and coffee intake and the modifying effect of sex, age, and smoking. Am. J. Clin. Nutr. 96: 182-187. http://dx.doi.org/10.3945/ajcn.111.027102

Sachse C, Brockmöller J, Bauer S and Roots I (1999). Functional significance of a C-->A polymorphism in intron 1 of the cytochrome P450 CYP1A2 gene tested with caffeine. Br. J. Clin. Pharmacol. 47: 445-449. http://dx.doi.org/10.1046/ j.1365-2125.1999.00898.x

Santos RM, Cotta K, Jiang S and Lima DRA (2015). Does CYP1A2 genotype influence coffee consumption? Austin J. Pharmacol. Ther. 3: 1065.

Sata F, Yamada H, Suzuki K, Saijo Y, et al. (2005). Caffeine intake, CYP1A2 polymorphism and the risk of recurrent pregnancy loss. Mol. Hum. Reprod. 11: 357-360. http://dx.doi.org/10.1093/molehr/gah175

Schmidt RJ, Romitti PA, Burns TL, Murray JC, et al.; National Birth Defects Prevention Study (2010). Caffeine, selected metabolic gene variants, and risk for neural tube defects. Birth Defects Res. A Clin. Mol. Teratol. 88: 560-569. http:// dx.doi.org/10.1002/bdra.20681

Sulem P, Gudbjartsson DF, Geller F, Prokopenko I, et al. (2011). Sequence variants at CYP1A1-CYP1A2 and AHR associate with coffee consumption. Hum. Mol. Genet. 20: 2071-2077. http://dx.doi.org/10.1093/hmg/ddr086

Tan EK, Chua E, Fook-Chong SM, Teo YY, et al. (2007). Association between caffeine intake and risk of Parkinson's disease among fast and slow metabolizers. Pharmacogenet. Genomics 17: 1001-1005. http://dx.doi.org/10.1097/ FPC.0b013e3282f09265

Tian O, Josse AR, Borchers C and El-Sohemy A (2013). Association between caffeine intake and the plasma proteome in humans. J. Caffeine Res. 3: 175-181. http://dx.doi.org/10.1089/jcr.2013.0025

Vink JM, Staphorsius AS and Boomsma DI (2009). A genetic analysis of coffee consumption in a sample of Dutch twins. Twin Res. Hum. Genet. 12: 127-131. http://dx.doi.org/10.1375/twin.12.2.127

Wang H, Zhang Z, Han S, Lu Y, et al. (2012). CYP1A2 rs762551 polymorphism contributes to cancer susceptibility: a metaanalysis from 19 case-control studies. BMC Cancer 12: 528. http://dx.doi.org/10.1186/1471-2407-12-528

Yamamoto VJ, de Paula VJR, Forlenza OV, dos Santos B, et al. (2015). Association study in Alzheimer's disease of single nucleotide polymorphisms implicated with coffee consumption. Arch. Clin. Psychiatry 42: 69-73. 